\title{
Compared characteristics of current vs. past smokers at the time of diagnosis of a first- time lung or head and neck cancer: a cross-sectional study
}

Corinne Vannimenus ${ }^{1 *}$, Hélène Bricout ${ }^{2}$, Olivier Le Rouzic ${ }^{1}$, François Mouawad ${ }^{3}$, Dominique Chevalier ${ }^{3}$, Eric Dansin ${ }^{4}$, Laurence Rotsaert ${ }^{4}$, Gautier Lefebvre ${ }^{4}$, Olivier Cottencin ${ }^{5}$, Henri Porte ${ }^{6}$, Arnaud Scherpereel ${ }^{1}$, Asmaa El Fahsi ${ }^{2}$, Florence Richard ${ }^{7}$, Benjamin Rolland ${ }^{8}$ (D) and The ALTAK Study Group

\begin{abstract}
Background: Active smoking at the time of diagnosis of a first head \& neck (H\&N) or lung cancer is associated with a worse cancer outcome and increased mortality. However, the compared characteristics of active vs. former smokers at cancer diagnosis are poorly known.

Methods: In 371 subjects with a first H\&N or lung cancer, we assessed: 1) socio-demographic features; 2) lifelong types of smoking; 3) alcohol use disorder identification test (AUDIT); 4) cannabis abuse screening test (CAST); and 5) Mini International Neuropsychiatric Interview (MINI). Using a multivariable regression model, we compared the profile of current smokers and past smokers.

Results: Current smokers more frequently exhibited H\&N cancer (OR 3.91;95\% Cl [2.00-6.51]; $p<0.0001)$ and ever smoking of hand-rolled cigarettes (OR 2.2; 95\% Cl [1.25-3.88]; $p=0.007)$. Among subjects with lung cancer $(n=177)$, current smoking was primarily associated with ever smoking of hand-rolled cigarettes (OR 2.88; $95 \% \mathrm{Cl}[1.32$ 6.30]; $p=0.008)$ and negatively associated with age (OR 0.92; 95\% Cl [0.89-0.96]; $p<0.001)$. Among subjects with H\&N cancer $(n=163)$, current smokers exhibited a significantly greater AUDIT score $(\mathrm{OR}=1.08 ; 95 \% \mathrm{Cl}[1.01-1.16] ; p=0.03)$.
\end{abstract}

Conclusion: At the time of diagnosis of the first lung or H\&N cancer, current smoking is highly associated with previous type of smoking and alcohol drinking patterns.

Trial registration: NCT01647425; Registration date: July 23, 2012.

Keywords: Tobacco use, Lung neoplasms, Head \& Neck Neoplasms, Alcohol-related disorders

\section{Background}

Tobacco smoking is the most important risk factor for lung cancer [1], while tobacco and alcohol conjointly account for the occurrence of $67-84 \%$ of the head and neck $(\mathrm{H} \& \mathrm{~N})$ cancers [2]. Continuing to smoke after the diagnosis of cancer is associated with higher risks of complications, secondary cancers, and death [3]. Moreover, in patients with a lung or $\mathrm{H} \& \mathrm{~N}$ cancer, persistent smoking is associated with decreased quality of life, general health,

\footnotetext{
* Correspondence: corinne.vannimenus@chru-lille.fr

${ }^{1}$ Service de Tabacologie, Clinique de Pneumologie, Hôpital Calmette, CHRU de Lille CS70001, 59037 Lille cedex, France

Full list of author information is available at the end of the article
}

and emotional and social functioning [4-6]. Intensive smoking cessation programs are thus warranted in current smokers with a first tobacco-related cancer [7].

In recent years, the implementation of tobacco control policies has enhanced the level of information on tobacco-related harm, which has promoted tobacco cessation [8], and subsequently reduced the incidence of tobacco-related cancers [9]. Despite the impact of such policies, some individuals continue to smoke tobacco until they experience a first-time tobacco-related health problem, including a first-time tobacco-related cancer. In contrast, some other individuals who experience a tobacco-related cancer had already stopped tobacco use 
long before the cancer diagnosis. Thus, the profile of patients with a first-time tobacco-related cancer can be divided into three categories at cancer diagnosis: 1) current smokers (CSs); 2) former smokers (FSs); and 3) never smokers.

Many previous studies have compared the profile of current vs. former smokers at the time of cancer diagnosis. A comprehensive review has recently listed these studies [10]. However, these studies essentially consisted of unadjusted analyses on the smoking status at cancer diagnosis, and, in most cases, they did not explore the contribution of the psychiatric history and other substance use patterns. Consequently, little is known about whether the smoking status at the time of diagnosis of a first-time lung or H\&N cancer is related to specific social or psychiatric features, lifelong smoking patterns, or history of other substance uses. In the non-cancer population, it was found that the overall outcome of tobacco dependence is associated with the age of first cigarette, lifelong smoking patterns, and poorer psychosocial conditions [11]. Moreover, concurrent psychiatric and other substance use disorders are also associated with a poorer outcome $[12,13]$. In patients with a first lung or $H \& N$ cancer, the role of these risk factors was never investigated. Enhancing the knowledge of the psychosocial determinants of the CS status among subjects with a first lung or $H \& N$ cancer could strengthen the impact of smoking cessation programs proposed to these patients.

In a multicenter one-year cohort study among 371 subjects with a first-time lung or $H \& N$ cancer (i.e., the ALTAK study), we conducted a cross-sectional study using the baseline assessment to investigate the differences in social factors, psychiatric condition, and other substance use patterns between current and pastsmokers at the time of the cancer diagnosis. The presentation of the study is provided according to the 'strengthening the reporting of observational studies in epidemiology' (STROBE) statement [14].

\section{Methods}

\section{Study design and centers}

Data used in this study originated from the baseline screening of the ALTAK cohort study, conducted among 372 subjects with a first lung or $H \& N$ cancer. Participants were recruited by otorhinolaryngologists, clinical oncologists, or pulmonologists of the participating centers, at the end of the consultation of cancer announcement. Physicians explained the study and received written consent for participation. The study took place between September 2012 and December 2014 in three different centers: 1) the Centre Oscar Lambret, i.e., the Regional Comprehensive Cancer Center of Lille; 2) the Department of Respiratory Diseases of the University Hospital of Lille; and 3) the Department of Otolaryngology-Head and Neck Surgery of the University Hospital of Lille.
The main objectives of the ALTAK cohort study were: 1) to measure the proportion of subjects that maintain tobacco smoking or alcohol abuse despite the occurrence of cancer; and 2) to identify the social and psychiatric features and addictive comorbidities that could constitute vulnerability factors for not stopping tobacco or alcohol after cancer diagnosis. More information on the study protocol can be found at https://clinicaltrials. gov/ct2/show/NCT01647425. Here, we have used the baseline data of the cohort to explore the determinants of the smoking status at time of cancer diagnosis.

\section{Participants and measures}

Inclusion criteria were: 1) age of 18 or more; 2) first lung or $\mathrm{H} \& \mathrm{~N}$ cancer excluding mesothelioma and esophagus cancer; and 3) no history of any other cancer over the last five years. The type of cancer (lung or H\&N), and the TNM classification grade [15] were noted by the clinician who received the initial consent.

Participants were assessed by an addiction specialist in the week following the announcement of the cancer diagnosis. The information collected at baseline and used in the present study was: 1) socioeconomic conditions: age, gender, familial status, employment, and educational level; 2) cancer status: localization, TNM grade, Eastern Cooperative Oncology Group / World Health Organization (ECOG/WHO) score; 3) smoking status and smoking habits: $C S$, i.e., at last one smoking episode in previous month; FS, i.e., no smoking episode over the previous month; and lifelong non-smoker; 4) alcohol use patterns: use of alcohol during the last 12 months (yes/ no); misuse of alcohol during the last 12 months (yes/ no), defined by an average alcohol use exceeding the recommended national thresholds, i.e., $\geq 210 \mathrm{~g}$ of alcohol per week for a man and $140 \mathrm{~g}$ for a woman, and $\geq 50 \mathrm{~g}$ per occasion for a man and $40 \mathrm{~g}$ for a woman [16], Alcohol Use Disorder Identification Test (AUDIT) [17]; 5) Severity of use of cannabis using the Cannabis Abuse Screening Test (CAST) [18], i.e., at least one positive item; and 6) Psychiatric assessment using the Mini International Neuropsychiatric Interview (MINI) [19], which is a validated structured interview for diagnosing mental health disorders.

\section{Statistical analyses}

Descriptive statistics of each variable are reported in Table 1. Quantitative values are presented as the mean (standard deviation [sd]) when normally distributed or as the median (interquartile range) when there is skewed distribution. Qualitative data are presented as n (percent). To compare smoker and ex-smoker groups, Student's t-test or the Kruskal-Wallis test were used for quantitative data, and the Chi-squared test or Fisher's exact test were used for categorical data. Logistic regression models were used 
Table 1 Descriptive statistics and univariate comparisons between current and past smokers at the time of the cancer onset

\begin{tabular}{|c|c|c|c|}
\hline & Past Smokers & Current Smokers & $p$-value \\
\hline Number of subjects (n; \%) & $177(52.1 \%)$ & $163(47.9 \%)$ & \\
\hline Gender (n females; \%) & $27(15.3 \%)$ & $35(21.5 \%)$ & 0.14 \\
\hline Age $(m \pm S D)$ & $61.9 \pm 9.7$ & $56.0 \pm 8.0$ & $<0.0001$ \\
\hline Educational level & & & 0.45 \\
\hline Elementary / primary school & 75 (42.4\%) & $68(41.7 \%)$ & \\
\hline Secondary / high school & $75(42.4 \%)$ & $77(47.2 \%)$ & \\
\hline Undergraduate and more/ college or university & $27(15.2 \%)$ & $18(11.1 \%)$ & \\
\hline Workers (n; \%) & $58(32.8 \%)$ & $98(60.1 \%)$ & $<0.0001$ \\
\hline Married (n; \%) & $124(70.1 \%)$ & $97(59.5 \%)$ & 0.04 \\
\hline Living alone (n; \%) & $35(19.8 \%)$ & $45(27.6 \%)$ & 0.09 \\
\hline \multicolumn{4}{|l|}{ Cancer } \\
\hline Localization & & & $<0.0001$ \\
\hline $1=$ lung & $119(67.2 \%)$ & $58(35.6 \%)$ & \\
\hline $2=$ head \& neck & $58(32.8 \%)$ & $105(64.4 \%)$ & \\
\hline "0" score at the ECOG performance status ( $n$; \%) & $77(43.5 \%)$ & $47(28.8 \%)$ & 0.005 \\
\hline TNM Grade $4(N=299)(n ; \%)$ & $97(59.2 \%)$ & $73(54.1 \%)$ & 0.38 \\
\hline Presence of metastases $(N=296)(n ; \%)$ & $72(44.7 \%)$ & $40(29.6 \%)$ & 0.008 \\
\hline \multicolumn{4}{|l|}{ Tobacco } \\
\hline Age of first cigarette (years; $m \pm S D$ ) & $15.6 \pm 3.8$ & $15.6 \pm 4.1$ & 0.95 \\
\hline \multicolumn{4}{|l|}{ Lifelong reported types of smoking, $(N=339)(n ; \%)$} \\
\hline Manufactured cigarettes & $172(97.2 \%)$ & $154(95.1 \%)$ & 0.31 \\
\hline Roll-up cigarettes & $64(36.2 \%)$ & $91(56.2 \%)$ & 0.0002 \\
\hline Cigarillos & $82(46.3 \%)$ & $58(35.8 \%)$ & 0.05 \\
\hline Cigars & $55(31.1 \%)$ & $40(24.7 \%)$ & 0.19 \\
\hline Pipe & $50(28.3 \%)$ & $26(16.1 \%)$ & 0.007 \\
\hline \multicolumn{4}{|l|}{ Alcohol } \\
\hline 12-month use (n; \%) & $140(79.1 \%)$ & $122(74.8 \%)$ & 0.35 \\
\hline 12-month misuse (n; \%) & $51(28.8 \%)$ & $70(42.9 \%)$ & 0.007 \\
\hline AUDIT, $(\mathrm{N}=322)$ (median [IQ]) & $4[2-6]$ & $6[2-11]$ & $0.002^{\mathrm{a}}$ \\
\hline AUDIT-C, (N = 322) (median [IQ]) & 4 [1-5] & $5[1-7]$ & $0.01^{\mathrm{a}}$ \\
\hline $\mathrm{CAST}(\mathrm{m} \pm \mathrm{SD})$ & $0.10 \pm 0.43$ & $0.22 \pm 0.59$ & $0.019^{a}$ \\
\hline \multicolumn{4}{|l|}{ MINI $5.0(N=337)$} \\
\hline TOTAL (n; \%) & $61(34.9 \%)$ & $72(44.4 \%)$ & 0.07 \\
\hline Current MDD (n; \%) & $23(13.1 \%)$ & 29 (17.9\%) & 0.22 \\
\hline Dysthymia (n; \%) & $2(1.1 \%)$ & $3(1.9 \%)$ & $0.67^{\mathrm{b}}$ \\
\hline Suicide risk (n; \%) & $39(22.3 \%)$ & $43(26.5 \%)$ & 0.36 \\
\hline Lifelong mania/hypomania (n; \%) & $2(1.1 \%)$ & $7(4.3 \%)$ & $0.09^{b}$ \\
\hline Schizophrenia (n; \%) & $10(5.7 \%)$ & $14(8.6 \%)$ & 0.30 \\
\hline Panic disorder/ agoraphobia (n; \%) & $16(9.1 \%)$ & $27(16.7 \%)$ & 0.04 \\
\hline Eating Disorder (n; \%) & $0(0.0 \%)$ & $0(0.0 \%)$ & NA \\
\hline Generalized anxiety (n; \%) & $7(4.0 \%)$ & $3(1.9 \%)$ & $0.34^{\mathrm{b}}$ \\
\hline Antisocial personality disorder ( $\mathrm{n} ; \%)$ & $0(0.0 \%)$ & $3(1.9 \%)$ & $0.12^{\mathrm{b}}$ \\
\hline
\end{tabular}


Table 1 Descriptive statistics and univariate comparisons between current and past smokers at the time of the cancer onset (Continued)

\begin{tabular}{llll}
\hline & Past Smokers & Current Smokers & $p$-value \\
\hline Obsessive-compulsive disorder $(n ; \%)$ & $1(0.6 \%)$ & $2(1.2 \%)$ & $0.61^{\mathrm{b}}$ \\
PTSD $(\mathrm{n} ; \%)$ & $1(0.6 \%)$ & $4(2.5 \%)$ & $0.20^{\mathrm{b}}$ \\
Other SUD $(\mathrm{n} ; \%)$ & $0(0.0 \%)$ & $1(0.6 \%)$ & $0.48^{\mathrm{b}}$
\end{tabular}

Abbreviations: AUDIT: Alcohol Use Disorder Identification Test, AUDIT-C: AUDIT "consumptions" i.e., the 3 first questions of the AUDIT, which pertain to the drinking levels, CAST: Cannabis Abuse Screening Test, ECOG: Eastern Cooperative Oncology Group, MINI: Mini International Neuropsychiatric Interview, version 5.0, TNM: Tumor/Nodules/Metastases, PTSD: Post-Traumatic Stress Disorder, SUD: Substance Use Disorder

*a " 0 " score at the ECOG performance status means "Fully active, able to carry on all predisease activities without restriction"

${ }^{a}$ Mann Whitney test

${ }^{\mathrm{b}}$ Fischer's exact test

to estimate OR with $95 \%$ confidence interval $(95 \% \mathrm{CI})$. A backward stepwise regression method was used to select variables (with $p<0.20$ ) associated with smoking status in a multiple logistic regression model, adjusted for age and sex. Significance levels were set at $p<0.05$. The final multiple logistic regression model was also stratified by localization. Analyses were performed using the SAS software release 9.02 (SAS Institute INC, Cary, NC, USA).

\section{Ethics approval}

The protocol of the ALTAK study (NCT01647425) was declared to and approved by the Comité de Protection des Personnes Nord-Ouest (\#CPP12/09) and the Agence Nationale des Médicaments et produits de santé (\#B111675-10).

\section{Results}

In total, 389 subjects were proposed to participate in the ALTAK study, of whom 371 accepted (response rate: 95 . 4\%). Among them, $163(43.9 \%)$ were CSs at the time of cancer diagnosis, and 177 (47.7\%) were PSs. The characteristics of these participants are summarized in Table 1, according to their smoking status. Bivariable comparisons between the CS and FS groups are also provided in Table 1.

Bivariable comparisons found that belonging to the CS group was significantly associated with younger age $(p<0.0001)$, being professionally active $(\mathrm{p}<0$. $0001)$, and being unmarried $(p=0.04)$. Moreover, the CS status was significantly associated with a $\mathrm{H} \& \mathrm{~N}$ localization of the cancer, with no alteration in daily life activities at the time of diagnosis $(p=0.005)$, and with the absence of metastases $(p=0.008)$. With respect to recent substance use patterns, being CS was associated with smoking roll-up cigarettes $(p<0.0002)$ , with reporting alcohol misuse in the past 12 months $(p=0.007)$ as well as with the AUDIT $(p=0.002)$ and AUDIT-C $(p=0.01)$ scores. Finally, the CS status was significantly associated with the CAST score for cannabis use $(p=0.019)$. By contrast, the CS status was not found associated with sex $(p=0.14)$, educational level $(p=0.45)$, or living alone $(p=0.09)$. Furthermore, being CS was not related to the age of first cigarette $(p=0.95)$ and the presence of any psychiatric disorder according to the MINI $(p=0.07)$.

A separate multivariable analysis of the CS status was conducted among patients with lung and $\mathrm{H} \& \mathrm{~N}$ cancer (see Table 2). In subjects with a lung cancer, the CS status was positively associated with ever use of hand-rolled cigarettes and negatively associated with age and ever use of cigarillos. There were trends for positive statistical associations between the CS status and positive MINI, never use of a pipe, and being single. In subjects with $H \& N$ cancer, the CS status was positively associated with the AUDIT score. Trends for positive statistical associations were found between the CS status and younger age, ever use of hand-rolled cigarettes, and never use of a pipe.

\section{Discussion}

The main objective of the study was to compare the sociodemographic features, psychiatric history, and substance use patterns, of CSs and FSs at the time of initial diagnosis of a first lung or $\mathrm{H} \& \mathrm{~N}$ cancer. The main results of the multivariable regression models were that the CS status was associated with younger age and ever use of hand-roll cigarettes in subjects with a first lung cancer, and increased AUDIT score in subjects with a first $\mathrm{H} \& \mathrm{~N}$ cancer. Overall, we found a prevalence of 43 . 9\% CSs, i.e., smokers over the preceding month. This figure is relatively consistent with the estimation provided by a recent literature review, which estimated approximately $50 \%$ the rate of CSs over the year preceding the diagnosis of a lung or H\&N cancer [10]. Though most of the studies have used a one-year period prior to cancer to define the CS status [10], we chose to follow the recommendations of the National Cancer Institute that deem a one-month period to be more precise [20].

Regarding the sociodemographic features of CSs, we have found in bivariable comparisons that being CS was significantly associated with younger age, being inactive, and being unmarried. Previous studies that explored the smoking status among subjects with a first lung or H\&N cancer found relatively similar results. For example, Schnoll et al. found that only a single marital status was 
Table 2 Association between patient characteristics and current smoking status. Logistic regression model adjusted for age and sex and stratified by localization

\begin{tabular}{|c|c|c|c|c|c|c|}
\hline & \multicolumn{3}{|c|}{ Lung cancer } & \multicolumn{3}{|c|}{ Head \& neck cancer } \\
\hline & OR & $95 \% \mathrm{Cl}$ & $p$-value & OR & $95 \% \mathrm{Cl}$ & $p$-value \\
\hline Age & 0.92 & $0.89-0.96$ & $<0.001$ & 0.97 & $0.92-1.01$ & 0.15 \\
\hline \multicolumn{7}{|l|}{ Marital status } \\
\hline Married or in couple & 1 & & & 1 & & \\
\hline Single or widowed & 0.49 & $0.23-1.07$ & 0.07 & 0.70 & $0.30-1.61$ & 0.40 \\
\hline \multicolumn{7}{|l|}{ Hand-rolled cigarettes } \\
\hline Never use & 1 & & & 1 & & \\
\hline Ever use & 2.88 & $1.32-6.30$ & 0.008 & 1.98 & $0.93-4.25$ & 0.08 \\
\hline \multicolumn{7}{|l|}{ Cigarillos } \\
\hline Never use & 1 & & & 1 & & \\
\hline Ever use & 0.43 & $0.19-0.97$ & 0.04 & 1.09 & $0.46-2.58$ & 0.85 \\
\hline \multicolumn{7}{|l|}{ Pipe } \\
\hline Never use & 1 & & & 1 & & \\
\hline Ever use & 0.46 & $0.16-1.37$ & 0.16 & 0.37 & $0.14-1.00$ & 0.05 \\
\hline AUDIT & 1.01 & $0.92-1.10$ & 0.87 & 1.08 & $1.01-1.16$ & 0.03 \\
\hline \multicolumn{7}{|l|}{ Psychiatric disorder } \\
\hline No & 1 & & & 1 & & \\
\hline Yes & 1.89 & $0.86-4.13$ & 0.11 & 1.36 & $0.60-3.11$ & 0.46 \\
\hline
\end{tabular}

significantly associated with increased CS status [21]. In subjects with H\&N cancer only, Duffy et al. found that smoking at cancer diagnosis was associated with younger age, single status, and lower education level [22]. Another study by the same team of authors also found that active smoking at the time of diagnosis of an H\&N cancer was associated with a single status, but not with age or education level [23].

Though younger age was not consistently found as a substantial contributor of the CS status in previous studies among subjects with lung or $H \& N$ cancer, it is a well-known factor in the general population, both in the US and in Europe [24, 25]. In this respective, our result could thus be reflective of this general finding. Moreover, the CS status was significantly more important among subjects with a $H \& N$ cancer, compared to those with a lung cancer.

Another important result was that the CS rate was much higher in the subjects with a first H\&N cancer than in those with a first lung cancer. To our knowledge, our study was the first to directly compare these two types of populations. The risk of experiencing a lung cancer, especially adenocarcinoma, is still significantly increased compared with never smokers more than 30 years after smoking cessation [26]. In contrast, quitting tobacco smoking fosters a more rapid decrease in the relative risk of $H \& N$ cancer [27]. The gap observed in the CS rates between lung and $H \& N$ cancer populations may thus be attributable to this difference in longitudinal risk reduction among FSs.

More importantly, it was recently noted that almost no previous studies have addressed the relative rates of the types of tobacco ever used among CSs and FSs with a lung or $H \& N$ cancer and that it was a significant issue to explore [10]. In this regard, our study is also the first to provide important findings on this subject. We have notably found that reporting ever smoking of roll-up cigarettes was highly associated with being a CS at the time of cancer diagnosis of a first lung cancer. In the French population, it has been previously found that $24.3 \%$ of smokers were used handrolling tobacco, while $7.5 \%$ of smokers use only this type of tobacco [28]. These figures are difficult to compare to other countries, as the prevalence of roll-you-own smokers is very variable depending on countries and their specific regulations on tobacco [29]. Regardless, in France, compared to smokers of manufactured cigarettes, handrolling smokers reported much lower average personal incomes and higher rates of unemployment [28]. This finding is consistent with other data out of France [30]. In the general population, it was previously shown that quitting smoking is inversely associated with impaired social conditions (10). Our findings in patients with cancer 
could thus be explained by unexplored social factors, even if our analyses were adjusted for the level of education.

Moreover, as early alterations in daily life activities and the presence of metastases at the time of cancer diagnosis were significantly associated with the FS status in bivariable comparisons, it could be suggested that the FS status is actually partially explained by symptom burden, in particular the fact that some people have become too sick to smoke before cancer was diagnosed. However, these two variables were involved in the step-by-step regression model, but they were not retained as relevant explanatory parameters by the modeling.

Finally, we identified that concurrent alcohol misuse, reflected by the AUDIT score, was significantly associated with the CS status only in patients with a H\&N cancer (see Table 2), which could be underlain by the fact that alcohol and tobacco are combined risk factors for this type of cancer.

Several limitations should be acknowledged with regard to the present study. First, the study was multicenter, but the recruitment was regional. Some findings could thus be skewed by local features. Moreover, patients with esophageal cancers were not included in the study, and thus, the findings cannot be applied to all types of H\&N cancers. Finally, we did not assess the use of non-smoking types of tobacco, notably chewing or snuff tobacco. However, this type of tobacco use is very rare in Europe [25]. The main objective of our study was to assess the lifelong types of tobacco used by the patients. This retrospective assessment could be found to be rather imprecise. However, a detailed and quantitative assessment of the specific periods of time during which each type of tobacco was used over the entire lifetime period would have been very difficult to carry out and would have suffered from memory bias and imprecision.

\section{Conclusions}

The study highlights important risk factors associated with a CS status at the time of diagnosis of a first lung or $H \& N$ cancer. Some risk factors are specific to $\mathrm{H} \& \mathrm{~N}$ cancer (i.e., concurrent alcohol misuse), whereas some others are associated with both types of cancer, i.e., young age, ever use of hand-rolled cigarettes, and possibly some psychiatric comorbidities. These findings should warrant a specific screening of these risk factors in subjects with a first lung or $H \& N$ cancer, with the aim to treat comorbid conditions and to act on impaired social situations, together with treating cancer and offering tobacco cessation programs to the patients.

\section{Abbreviations}

AUDIT: Alcohol Use Disorders Identification Test; CAST: Cannabis Abuse Screening Test; CSs: Current Smokers; ECOG: Eastern Cooperative Oncology Group; FSs: Former Smokers; H\&N: Head and Neck; MINI: Mini International Neuropsychiatric Interview; STROBE: 'Strengthening The Reporting of OBservational studies in Epidemiology'; WHO: World Health Organization

\section{Acknowledgements \\ The authors wish to thank Françoise WEINGERTNER, Stéphanie CLISANT, and Yvette VENDEL for their significant organizational help. The ALTAK Study Group is composed of the following members: Corinne VANNIMENUS, Françoise WEINGERTNER, Hélène BRICOUT, Olivier LE ROUZIC, François MOUAWAD, Dominique CHEVALIER, Eric DANSIN, Stéphanie CLISANT, Laurence ROTSAERT, Gautier LEFEBVRE, Olivier COTTENCIN, Henri PORTE, Arnaud SCHERPEREEL, Asmaa EL FAHSI, Dienabou SYLLA, Florence RICHARD, and Benjamin ROLLAND.}

\section{Funding}

ALTAK was funded by the Institut National du Cancer (INCa): Grant \#RECF1764. The study design and the conduct of the study are independent and remain the full responsibility of the investigators.

Availability of data and materials

Data and materials can be requested at corinne.vannimenus@chru-lille.fr

\section{Authors' contributions}

$\mathrm{BR}$, HB, FR, and CV designed the study and obtained the grant. CV was the grant holder. CV, AEF, OC, OLR, FM, DC, ED, GL, HP, AS, and LR collected the data. $B R, H B$, and $F R$ performed the statistical analyses. BR wrote the first draft of the manuscript. CV, HB, FR, OLR, FM, DC, ED, LR, GL, OC, HP, AS, AEF were involved in revising the manuscript critically. All authors have read and approved the final version of the manuscript, and have agreed to be accountable for all aspects of the work in ensuring that questions related to the accuracy or integrity of any part of the work are appropriately investigated and resolved.

Ethics approval and consent to participate

The protocol of the ALTAK study (NCT01647425) was declared to and approved by the Comité de Protection des Personnes Nord-Ouest (\#CPP12/ 09) and the Agence Nationale des Médicaments et produits de santé (\#B111675-10). All participants gave their written consent for participating in the study.

\section{Consent for publication}

Not Applicable.

\section{Competing interests}

The authors declare that they have no competing interests.

\section{Publisher's Note}

Springer Nature remains neutral with regard to jurisdictional claims in published maps and institutional affiliations.

\section{Author details}

'Service de Tabacologie, Clinique de Pneumologie, Hôpital Calmette, CHRU de Lille CS70001, 59037 Lille cedex, France. ${ }^{2}$ Centre de Référence Régionale en Cancérologie, Lille, France. ${ }^{3}$ Service d'Oto-rhino-laryngologie, CHRU de Lille, Lille, France. ${ }^{4}$ Département de Cancérologie Cervico-Faciale, Centre de Lutte Contre le Cancer Oscar Lambret, Lille, France. ${ }^{5}$ Service d'Addictologie, CHRU de Lille, Lille, France. ${ }^{6}$ Clinique de Chirurgie Thoracique, CHRU de Lille, Lille, France. ${ }^{7}$ Santé Publique et Epidémiologie, Institut Pasteur, Université de Lille, INSERM UMR744, Lille, France. ${ }^{8}$ Univ Lyon; UCBL; INSERM U1028; CNRS UMR5292 ; Service Universitaire d'Addictologie de Lyon, CH le Vinatier, Lyon, France.

Received: 21 August 2017 Accepted: 20 March 2018

Published online: 03 April 2018

\section{References}

1. Alberg AJ, Samet JM. Epidemiology of lung cancer. Chest. 2003;123(1 Suppl):21S-49S. 
2. Anantharaman D, Marron M, Lagiou P, Samoli E, Ahrens W, Pohlabeln H, et al. Population attributable risk of tobacco and alcohol for upper aerodigestive tract cancer. Oral Oncol. 2011;47(8):725-31.

3. Toll BA, Brandon TH, Gritz ER, Warren GW, Herbst RS. AACR Subcommittee on tobacco and Cancer. Assessing tobacco use by cancer patients and facilitating cessation: an American Association for Cancer Research policy statement. Clin Cancer Res. 2013;19(8):1941-8.

4. Gritz ER, Carmack CL, de Moor C, Coscarelli A, Schacherer CW, Meyers EG, et al. First year after head and neck cancer: quality of life. J Clin Oncol. 1999; 17(1):352-60.

5. Duffy SA, Terrell JE, Valenstein M, Ronis DL, Copeland LA, Connors M. Effect of smoking, alcohol, and depression on the quality of life of head and neck cancer patients. Gen Hosp Psychiatry. 2002;24(3):140-7.

6. Garces YI, Schroeder DR, Nirelli LM, Croghan GA, Croghan IT, Foote RL, et al. Tobacco use outcomes among patients with head and neck carcinoma treated for nicotine dependence: a matched-pair analysis. Cancer. 2004; 101(1):116-24

7. Karam-Hage M, Cinciripini PM, Gritz ER. Tobacco use and cessation for cancer survivors: an overview for clinicians. CA Cancer J Clin. 2014;64(4): 272-90

8. Farrelly MC, Pechacek TF, Thomas KY, Nelson D. The impact of tobacco control programs on adult smoking. Am J Public Health. 2008;98(2):304-9.

9. Jemal A, Cokkinides VE, Shafey O, Thun MJ. Lung cancer trends in young adults: an early indicator of progress in tobacco control (United States). Cancer Causes Control. 2003;14(6):579-85.

10. Burris $J$, Studts JL, DeRosa AP, Ostroff JS. Systematic review of tobacco use after lung or head/neck Cancer diagnosis: results and recommendations for future research. Cancer Epidemiol Biomark Prev. 2015;24(10):1450-61.

11. Vangeli E, Stapleton J, Smit ES, Borland R, West R. Predictors of attempts to stop smoking and their success in adult general population samples: a systematic review. Addiction. 2011;106(12):2110-21.

12. Goodwin RD, Pagura J, Spiwak R, Lemeshow AR, Sareen J. Predictors of persistent nicotine dependence among adults in the United States. Drug Alcohol Depend. 2011;118(2-3):127-33.

13. Goodwin RD, Kim JH, Weinberger AH, Taha F, Galea S, Martins SS. Symptoms of alcohol dependence and smoking initiation and persistence: a longitudinal study among US adults. Drug Alcohol Depend. 2013;133(2): 718-23.

14. von Elm E, Altman DG, Egger M, Pocock SJ, Gøtzsche PC, Vandenbroucke $J$, et al. The strengthening the reporting of observational studies in epidemiology (STROBE) statement: guidelines for reporting observational studies. Lancet. 2007;370(9596):1453-7.

15. Travis WD, Giroux DJ, Chansky K, Crowley J, Asamura H, Brambilla E, et al. The IASLC lung Cancer staging project: proposals for the inclusion of broncho-pulmonary carcinoid tumors in the forthcoming (seventh) edition of the TNM classification for lung Cancer. J Thorac Oncol. 2008;3(11):1213-23.

16. French Alcohol Society. Good Practice Recommendations. Alcohol misuse: screening, diagnosis and treatment. 2015. http://www.sfalcoologie.asso.fr/ download/SFA-GPR-AlcoholMisuse.pdf?PHPSESSID=4e400010332fdc95b 8572ae6e0e7d9d7 (Accessed 10 Jul 2017).

17. Saunders JB, Aasland OG, Babor TF, de la Fuente JR, Grant M. Development of the alcohol use disorders identification test (AUDIT): WHO collaborative project on early detection of persons with harmful alcohol consumption-II. Addiction. 1993;88(6):791-804.

18. Legleye S, Karila L, Beck F, Reynaud M. Validation of the CAST, a general population Cannabis abuse screening test. J Subst Use. 2007;12(4):233-42.

19. Sheehan DV, Lecrubier $Y$, Sheehan $\mathrm{KH}$, Amorim $\mathrm{P}$, Janavs J, Weiller $\mathrm{E}$, et al. The Mini-International Neuropsychiatric Interview (M.I.N.I.): the development and validation of a structured diagnostic psychiatric interview for DSM-IV and ICD-10. J Clin Psychiatry. 1998;59(Suppl 20):22-33. quiz 34-57

20. National Cancer Institute, American Association for Cancer Research. NCl-AACR cancer patient tobacco use questionnaire. https:/www.gem-measures.org/ Public/DownloadMeasure.aspx?mid=2003 (Accessed 20 July 2017).

21. Schnoll RA, James C, Malstrom M, Rothman RL, Wang H, Babb J, Miller SM, Ridge JA, Movsas B, Langer C, Unger M, Goldberg M. Longitudinal predictors of continued tobacco use among patients diagnosed with cancer. Ann Behav Med. 2003;25(3):214-22.

22. Duffy $\mathrm{SA}$, Ronis $\mathrm{DL}$, Valenstein $\mathrm{M}$, Fowler KE, Lambert MT, Bishop C, Terrell JE. Depressive symptoms, smoking, drinking, and quality of life among head and neck cancer patients. Psychosomatics. 2007;48(2):142-8.
23. Duffy SA, Khan MJ, Ronis DL, Fowler KE, Gruber SB, Wolf GT, Terrell JE. Health behaviors of head and neck cancer patients the first year after diagnosis. Head Neck. 2008;30(1):93-102.

24. American Lung Association. Trends in Tobacco Use. 2011. http://www.lung.org/ assets/documents/research/tobacco-trend-report.pdf (Accessed 20 July 2017).

25. European Commission. Special Eurobarometer 385: « Attitudes of European towards tobacco ». 2012. http://ec.europa.eu/health/tobacco/docs/ eurobaro_attitudes_towards_tobacco_2012_en.pdf. (Accessed 20 July 2017).

26. Ebbert JO, Yang P, Vachon CM, Vierkant RA, Cerhan JR, Folsom AR, et al. Lung cancer risk reduction after smoking cessation: observations from a prospective cohort of women. J Clin Oncol. 2003;21(5):921-6.

27. Marron M, Boffetta P, Zhang Z-F, Zaridze D, Wünsch-Filho V, Winn DM, et al. Cessation of alcohol drinking, tobacco smoking and the reversal of head and neck cancer risk. Int J Epidemiol. 2010;39(1):182-96.

28. Guignard R, Beck F, Richard JB, Peretti-Watel P. Le tabagisme en France: analyse de l'enquête Baromètre santé 2010 [Tobacco use in France: results of the 2010 "Health Barometer"].. Saint-Denis, Inpes, coll. Baromètres santé, 2013: 56 p. http://inpes.santepubliquefrance.fr/CFESBases/catalogue/pdf/ 1513.pdf (Accessed 24 Dec 17).

29. Young D, Borland R, Hammond D, Cummings KM, Devlin E, Yong HH, O'Connnor RJ, ITC Collaboration. Prevalence and attributes of roll-your-own smokers in the international tobacco control (ITC) four country survey. Tob Control. 2006;15(Suppl 3):iii76-82.

30. Curti D, Shang C, Ridgeway W, Chaloupka FJ, Fong GT. The use of legal, illegal and roll-your-own cigarettes to increasing tobacco excise taxes and comprehensive tobacco control policies: findings from the ITC Uruguay survey. Tob Control. 2015;24(Suppl 3):iii17-24.

\section{Submit your next manuscript to BioMed Central and we will help you at every step:}

- We accept pre-submission inquiries

- Our selector tool helps you to find the most relevant journal

- We provide round the clock customer support

- Convenient online submission

- Thorough peer review

- Inclusion in PubMed and all major indexing services

- Maximum visibility for your research

Submit your manuscript at www.biomedcentral.com/submit
Biomed Central 